\title{
Onderwijs aan Nijmeegse studenten geneeskunde in vaardigheden voor Eerste Hulp
}

\author{
P.A. de Ruijter, S.F.L. van Stigt, J. Biert, E.C.T.H. Tan
}

\section{Samenvatting}

Van (toekomstige) artsen wordt verwacht dat zij de eerstehulpverlening beheersen. Uit diverse onderzoeken is gebleken dat studenten geneeskunde over onvoldoende vaardigheden beschikken bij het verlenen van basale eerste hulp en elementaire reanimatie. Bij de (landelijke) invoering van de Bachelor/Masterstructuur (BaMa) in de opleiding Geneeskunde aan het UMC St Radboud, werd een verplichte EHBO-cursus opgenomen in de bachelorfase. Deze blokoverstijgende cursus van 35 studiebelastinguren (SBU) bestaat voor de eerstejaars uit acht avondlessen van twee uur, een theorietoets en een praktijkexamen in de vorm van een stationstoets.

Naast de basale reanimatie - geheel volgens de huidige richtlijnen van de Nederlandse Reanimatie Raad - worden diverse levensreddende handelingen, het aanleggen van verbanden en de systematische benadering van (ongevals-) slachtoffers behandeld. Hierdoor leert de student op minimaal het niveau van de leek extramuraal eerste hulp te verlenen, zonder gebruik te maken van (ingewikkelde) hulpmiddelen. In het tweede jaar volgt een herhalingscursus van vier uur, waarbij tevens geoefend wordt met de Automatische Externe Defibrillator (AED). In het derde jaar volgt nogmaals een herhalingscursus van vier uur en wordt de kinderreanimatie gedoceerd.

De cursus wordt gegeven door student-instructeurs, die in dienst zijn als student-assistent bij het UMC St Radboud. De organisatie van de cursus is in handen van een vifftal (tweedetot zesdejaars-)studenten, die onder verantwoordelijkheid van stafleden (twee chirurg-traumatologen, een huisarts en een anesthesioloog) uit het UMC St Radboud werken. Er zijn inmiddels goede ervaringen opgedaan met de inzet van student-assistenten. De gebruikte methode blijkt in de praktijk goed te werken en wordt door studenten positief gewaardeerd. (Ruijter PA de, Stigt SFL van, Biert J, Tan ECTH. Onderwijs aan Nijmeegse studenten geneeskunde in vaardigheden voor Eerste Hulp. Tijdschrift voor Medisch Onderwijs 2009;28(2):74-80.)

\section{Inleiding}

Bij de invoering van het vorige curriculum geneeskunde aan de medische faculteit van de Radboud Universiteit Nijmegen (UMC St Radboud) in 1982 was er geen plaats meer voor praktisch gericht EHBOonderwijs. De toenmalige intracurriculaire EHBO-cursus werd overgenomen door de Medische Faculteits Vereniging Nijmegen (MFVN). Studenten konden daar op vrijwillige basis aan deelnemen. Ook bij de herziening van het curriculum in 1995 bleef de EHBO-cursus facultatief.
Bij de invoering van de Bachelor/Masterstructuur (BaMa) in het studiejaar 2005/ 2006, kreeg de EHBO-cursus weer een plek in het reguliere curriculum geneeskunde. Besloten werd de cursus - met enkele wijzigingen - onder de noemer 'Vaardigheden Acute Geneeskunde/EHBO' (VAG/ EHBO) op te nemen. Daarbij werd vastgehouden aan het principe dat de cursus voor het grootste deel georganiseerd wordt voor en door studenten. Redenen voor opname van een EHBO-cursus in het curriculum geneeskunde waren onder meer 
de gestelde eisen in het Raamplan ${ }^{1}$ en diverse (eigen) onderzoeken waarin naar voren kwam dat studenten geneeskunde en coassistenten de vaardigheden van eerste hulp slecht beheersen en zich onzeker voelen over het eigen kunnen in een acute situatie. ${ }^{2-4}$ Bewust werd gekozen voor het opnemen van de cursus in het eerste jaar van de bachelorfase, zodat in een vroeg stadium een basis wordt gelegd waarop in de rest van de opleiding voortgebouwd kan worden.

\section{Organisatie}

De organisatie en uitvoering van het blok VAG/EHBO is in handen van een groep (tweede- tot en met zesdejaars-)studenten geneeskunde, onder verantwoordelijkheid van stafleden uit het UMC St Radboud. Deze blokcommissie bestaat uit twee chirurg-traumatologen, een huisarts, een anesthesioloog-intensivist en vijf studentleden. De taken van de blokcommissie zijn de organisatie van het blok, het schrijven en up-to-date houden van het blokboek en de supervisie over de student-instructeurs. Circa 30 student-instructeurs geven zelfstandig onderwijs aan groepen van 15 studenten. Zij dragen zelf de verantwoordelijkheid voor de indeling van de lessen, de behandeling van de leerstof en de diverse vaardigheden. De nadruk ligt in de lessen op de praktijk; elke week moet de mogelijkheid aanwezig zijn de elementaire reanimatie Basic Life Support (BLS) - te oefenen.

\section{Inzet van student-assistenten}

Waar de student-instructeurs voor de door de MFVN georganiseerde cursus een onkostenvergoeding ontvingen, zijn zij in de huidige opzet als student-assistent in dienst bij het Onderwijsinstituut van het UMC St Radboud. Werving en selectie van nieuwe instructeurs vindt plaats in een selectieronde van drie avonden waarbij geïnteresseerde studenten door student- instructeurs en blokcommissieleden worden beoordeeld op didactische vaardigheden, theoretische kennis en motivatie. Aan de hand van de resultaten van de selectieavonden wordt het benodigde aantal aspirant-instructeurs geselecteerd. Om student-instructeur te kunnen worden moet de student geslaagd zijn voor de toetsen in de cursus en in positieve zin opgevallen zijn in de lessen.

De opleiding tot student-instructeur bestaat naast vier verdiepingsavonden voor verfijning van theorie en praktijkvaardigheden uit een stage van acht lessen bij een ervaren instructeur in de cursus, waarbij na vier lessen van groep gewisseld wordt. Er is een afsluitend examen waarin zowel didactiek als theorie en praktijk getoetst worden.

Om de kwaliteit van het gegeven onderwijs te garanderen, worden de student-instructeurs zorgvuldig opgeleid en regelmatig (drie maal per jaar) bijgeschoold en getoetst op vaardigheden en kennis. Daarnaast wordt gebruik gemaakt van peer review (het geven van onderlinge feedback) door de studentleden van de blokcommissie, zodat student-instructeurs feedback krijgen op hun vaardigheden in de les. De arts-docenten uit de blokcommissie houden toezicht op de uitvoering van het onderwijs en dragen de eindverantwoordelijkheid voor de cursus.

Inzet van student-assistenten bij onderwijs in basale reanimatie en eerste hulp is niet nieuw ${ }^{5}$ en student-assistenten blijken hiertoe heel goed in staat. ${ }^{6-7}$ Een beperking bij de inzet van student-assistenten is hun relatief korte inzetbaarheid door de in de BaMa-structuur vervroegde start van de coschappen, waardoor er weinig tijd is ruime ervaring op te doen. Gebrek aan overwicht, diepgang in kennis en ervaring in daadwerkelijke eerste hulp lijkt zelden een struikelblok. 


\section{Opzet en inhoud van de cursus}

Het blok VAG/EHBO is verplicht voor alle eerstejaarsstudenten geneeskunde, wat neerkomt op 365 cursisten per jaar. De uit acht lessen van twee uur bestaande cursus wordt in de avonduren gegeven en wordt afgesloten met een theorie- en praktijkexamen. Voor het blok staan 35 Studiebelastinguren (SBU) ter beschikking. Voor het behalen van de propedeuse is het met een voldoende afsluiten van de cursus een vereiste. Een cursusgroep bestaat uit 15 studenten die begeleid worden door één student-instructeur en één aspirant-instructeur. Gedurende de hele cursus blijft dezelfde student-instructeur bij de groep; de aspirant-instructeur wisselt na vier avonden van groep.

Uitgangspunt bij het selecteren van de lesstof van deze cursus is dat de student geneeskunde moet worden voorbereid op spoedeisend handelen buiten de muren van het ziekenhuis. Zodoende omvat het blokboek alle stof die ook in reguliere EHBO-cursussen gegeven wordt, zoals die van het Rode en Oranje Kruis ${ }^{8-9}$, en sluit het aan bij professionele hulpverlening op straat conform de Landelijke Protocollen van de Ambulancedienst (LPA versie 7). Zie Box 1 voor inhoud van de cursus. Daar de doelgroep 'studenten geneeskunde' echter meer diepgang vraagt, is een aantal onderwerpen aan de stof toegevoegd. Daarbij wordt in het oog gehouden dat het een basiscursus EHBO betreft en er géén risicovolle of voorbehouden handelingen worden aangeleerd. Alle stof is conform de internationaal geldende richtlijnen voor EHBO en BLS en wordt jaarlijks aangepast aan nieuw verschenen richtlijnen. . $^{8-11}$

In de cursus is veel aandacht voor het handelen in de praktijk en de studenten wordt ook geleerd praktisch te werken en te denken. Om studenten handvatten te geven bij de benadering van een slachtoffer wordt gebruik gemaakt van een pro- tocol dat is afgeleid van de ATLS ${ }^{\circledR}$-richtlijnen ${ }^{12}$ (hetgeen een vereiste is volgens het Raamplan ${ }^{1}$ ). Het ABCDE-protocol (Airway-Breathing-Circulation-Disability en Exposure) zorgt er voor dat de student handelt volgens het ATLS $^{\circledR}$-principe 'treat first what kills first', waarbij levensbedreigende aandoeningen die tijdens het onderzoek gevonden worden, eerst behandeld dienen te worden. Ook stimuleert het protocol dat de student een (ongevals-)slachtoffer systematisch benadert en daardoor in een stressvolle situatie minder snel belangrijke zaken mist.

Om praktijksituaties zo goed mogelijk te benaderen wordt in deze cursus gebruik gemaakt van LOTUS-slachtoffers (Landelijke Opleiding Tot Uitbeelding van Slacht-

\section{Box 1. Globaal overzicht behandelde stof.}

\begin{tabular}{|l|}
\hline Basic Life Support \\
Reanimatie volwassenen \\
Heimlich-manoeuvre \\
Stabiele zijligging \\
Algemene regels EHBO \\
Stoornissen in het Bewustzijn \\
Bewusteloosheid, syncope \\
Traumatisch schedel/hersenletsel \\
Cerebro Vasculair Accident \\
Diabetes mellitus \\
Epilepsie \\
Stoornissen in de Ademhaling \\
Astma \\
Hyperventilatie \\
Zuigende borstwond en pneumothorax \\
Stoornissen in de Circulatie \\
Ernstig uitwendig bloedverlies \\
Shock \\
Myocardinfarct en angina pectoris \\
Stoornissen in de Neurologie \\
Wervelletsels en dwarslaesie \\
Warmte/Koudeletsels en Thermische letsels \\
Verbandleer en Basishandelingen EHBO \\
Ketenzorg
\end{tabular}


offers). De cursist leert daardoor enerzijds specifieke ziektebeelden beter te herkennen en wordt anderzijds in de gelegenheid gesteld het protocol in een 'echte' praktijksituatie toe te passen. De psychosociale problematiek van het slachtoffer wordt daarbij zo goed mogelijk nagebootst. Er zijn twee speciale LOTUS-avonden tijdens de cursus, waarbij de eerste avond in het teken staat van enkele relatief eenvoudige letsels, zoals een verstuikte enkel, een snijwond en een brandwond. Gedurende de tweede avond oefenen de studenten met de LOTUS-slachtoffers in een aantal situaties met meerdere slachtoffers, waarbij in groepjes hulp wordt geboden.

\section{Toetsing en beoordeling}

Toetsing is een belangrijk deel van het medisch onderwijs. In de eerste jaren van de opleiding tot arts ligt het zwaartepunt bij de meeste vakken op de theoretische kennis. Bij de eerstehulpverlening ligt de nadruk echter op de praktijk. Immers, in een acute situatie zal men snel en adequaat moeten handelen om schade en verergering van de toestand van het slachtoffer te voorkomen. In de cursus VAG/EHBO worden praktische vaardigheden en theoretische kennis afzonderlijk getoetst. De theoretische kennis wordt getoetst met een theorietoets van 70 meerkeuzevragen zowel over de stof uit het blokboek als over de aanvullende informatie die digitaal (Blackboard) wordt aangeboden. De betrouwbaarheid van een theorietoets wordt afgemeten aan de coefficiënt alfa, waarbij een alfa van tenminste 0.80 wordt nagestreefd om in redelijke mate een uitspraak te kunnen doen over het kennisniveau van de student. Bij de twee theorietoetsen uit studiejaar 2007/ 2008 (de cursus wordt twee keer per studiejaar gegeven) bleek de alfawaarde respectievelijk 0.68 en 0.64 . Het hoge slagingspercentage en de relatief lage alfawaarden worden waarschijnlijk veroorzaakt door de relatief eenvoudige stof van de cursus. De praktijk wordt getoetst met een stationstoets bestaande uit drie stations:

- Praktijksituatie met LOTUS-slachtoffer, bijvoorbeeld in een ongevalssituatie, waarbij integratief het aangepaste ABCDE-protocol getoetst wordt.

- Handeling en verband, waarbij de student gevraagd wordt een handeling uit te voeren, zoals het positioneren van de patiënt in stabiele zijligging en het aanleggen van een verband, zoals het enkeldrukverband.

- BLS, waarbij getoetst wordt of de student de juiste benadering en de basale vaardigheden van de elementaire reanimatie voldoende beheerst. ${ }^{10}$

Ieder van de bovengenoemde stations duurt tien minuten, waardoor de praktijktoets een half uur in beslag neemt. Het praktijkexamen wordt afgenomen door student-instructeurs volgens een strikt protocol onder supervisie van arts-docenten uit de blokcommissie die tevens beschikbaar zijn voor overleg. De exameneisen zijn vastgesteld door de blokcommissie. Ze vergen het correct gebruik van het protocol, het correct uitvoeren van benodigde levensreddende handelingen en het adequaat verlenen van eerste hulp conform de geldende richtlijnen. ${ }^{8-11} 13$

Indien een student de eerste keer niet slaagt voor het examen (in 2006/2007 slaagde $47 \%$ bij de eerste toetsgelegenheid), is er twee weken later de gelegenheid opnieuw examen te doen (zie Tabel 1). Tussen de eerste ronde en de herkansingsronde wordt de cursist in de gelegenheid gesteld het feedbackformulier van de praktijktoets in te zien en onder begeleiding van student-instructeurs specifieke onderdelen van de toets te oefenen. Na de herkansing is $99 \%$ van de studenten geslaagd voor het praktijkgedeelte. Het grote percentage gezakte studenten na het eerste examen 
Onderwijs in vaardigheden Eerste Hulp $\mid$ P.A de Ruijter et al.

Tabel 1. Resultaten toetsen in de cursus en einduitslag.*

\begin{tabular}{lccccc}
\hline & $\begin{array}{c}\text { Geslaagd } \\
\text { praktijk } \\
\text { eerste toets }\end{array}$ & $\begin{array}{c}\text { Geslaagd } \\
\text { theorie eerste } \\
\text { toets }\end{array}$ & $\begin{array}{c}\text { Geslaagd } \\
\text { praktijk na } \\
\text { hertoets }\end{array}$ & $\begin{array}{c}\text { Geslaagd } \\
\text { theorie na } \\
\text { hertoets }\end{array}$ & $\begin{array}{c}\text { Einduitslag } \\
\text { studenten } \\
\text { geslaagd }\end{array}$ \\
\hline Studiejaar & $165 / 352$ & $337 / 352$ & $349 / 352$ & $351 / 352$ & $348 / 352$ \\
2006/2007 & $(46,9 \%)$ & $(95,7 \%)$ & $(99,2 \%)$ & $(99,7 \%)$ & $(98,9 \%)$ \\
Studiejaar & $163 / 350$ & $332 / 350$ & $333 / 350$ & $347 / 350$ & $330 / 350$ \\
2007/2008 & $(46,6 \%)$ & $(94,9 \%)^{*}$ & $(95,1 \%)$ & $(99,1 \%)$ & $(94,3 \%)$ \\
\hline
\end{tabular}

* Betrouwbaarheid theorietoetsen in studiejaar 2007/2008: gemiddelde coëfficiënt alfa 0.66.

wordt mogelijk veroorzaakt door gebrek aan ervaring bij studenten met praktijktoetsing, door onderschatting van de toets en door de relatief strenge normen. Een vergelijking met andere EHBO-cursussen is hier lastig te maken, omdat deze opzet alleen op onze faculteit wordt gebruikt. Het theoriegedeelte wordt herkanst tijdens de reguliere herkansingsweken in de zomermaanden.

\section{Herhaling en oefening in het tweede jaar}

In het tweede jaar vindt een herhaaloefening plaats, waarbij de studenten opnieuw de gelegenheid krijgen te oefenen met realistische casuïstiek, en wederom gebruik gemaakt wordt van LOTUS-slachtoffers. De casus wordt onder leiding van een instructeur geëvalueerd en er wordt eventueel verdieping geboden. Op dezelfde avond wordt ook een reanimatietoets afgenomen, waarvan de student op de tweede avond, twee weken later, de uitslag krijgt. De tweede avond staat in het teken van het herhalen van de reanimatievaardigheden en het leren gebruiken van de Automatische Externe Defibrillator (AED). Voor het herhalingsonderwijs in het tweedejaar zijn 15 SBU gereserveerd. In studiejaar 2008/2009 is deze opzet enigszins gewijzigd: er vinden twee herhaalmomenten van twee uur plaats, met een interval van vijf maanden. Op beide avonden wordt geoefend met de LOTUS-slachtoffers, de reanimatie wordt herhaald en er wordt geleerd met de AED om te gaan.

\section{Ervaringen van cursisten}

De cursus wordt door de deelnemende studenten als zeer zinvol ervaren en ook zeer positief geëvalueerd (E-survey). Voor velen is het een eerste kennismaking met eerstehulpverlening en met het praktijkonderwijs in de opleiding tot arts. Ook het feit dat het onderwijs door student-instructeurs wordt gegeven wordt door weinig cursisten als een probleem ervaren. Zij geven juist aan dit als positief te ervaren. Student-instructeurs kunnen zich beter inleven in de cursisten, zijn laagdrempelig voor het stellen van vragen en de sfeer tijdens de les is erg ontspannen. Deze bevindingen komen overeen met andere beschreven onderzoeken. ${ }^{5}$ Voor sommige cursisten blijkt het lastig dat de cursus in de avonduren gegeven wordt, met name om logistieke redenen. Bij aanvang van de cursus blijkt ongeveer 97\% van de aangemelde studenten te starten met de cursus, ongeveer 95\% doet daadwerkelijk examen. Uitval (3-5\%) wordt onder andere veroorzaakt door het staken van de studie of door het niet voldoen aan de aanwezigheidsverplichting op zes van de acht lesavonden. Dit lijkt consistent te zijn met andere verplichte onderwijsonderdelen aan onze 
faculteit. In enquêtes, gehouden door het Onderwijsinstituut van het UMC St Radboud onder deelnemende studenten, werd de cursus na de eerste twee loopjaren respectievelijk met een 7,5 en een 8 beoordeeld op een schaal van 1-10 in de E-survey.

\section{Conclusie}

De aan het UMC St Radboud gebruikte methode voor onderwijs in 'elementaire eerste hulp en basale reanimatie' lijkt in de praktijk goed te werken. Het daadwerkelijke effect van het onderwijs op de kennis en vaardigheden van de studenten in het verlenen van basale reanimatie en eerste hulp wordt op dit moment nader geëvalueerd. De studenten ervaren de cursus als zeer positief en in ruim drie jaar tijd is veel ervaring opgedaan met de inzet van student-assistenten bij het EHBO-onderwijs aan studenten geneeskunde. Studentinstructeurs zijn doorgaans flexibel inzetbaar, toegankelijk voor studenten en goedkoop ten opzichte van arts-docenten.

\section{Literatuur}

1. Metz JCM, Verbeek-Weel AMM, Huisjes HJ. Blueprint 2001: Training of Doctors. Adjusted objectives of undergraduate Medical Education in The Netherlands. Nijmegen: University Publication Office, University of Nijmegen; 2001.

2. Tan ECTH, Hekkert KD, van Vugt AB, Biert J. Is er een dokter in de Zaal? Med Contact 2007;62: 391-393. [Is there a doctor in the room? Medical Contact 2007;62:391-393].

3. Tan ECTH, Hekkert KD, van Vugt AB, Biert J. First Aid and BLS, A questionnaire survey of Medical Schools in the Netherlands. Teaching and Learning in Medicine, accepted for publication in 2008

4. Tan ECTH, Severien I, Metz JCM, Berden HJJM and Biert J. First aid and basic life support of junior doctors: A prospective study in Nijmegen, the Netherlands. Med Teach 28:2,189-192.

5. Perkins GD, Hulme J, Shore HR, Bion JF. Basic life support training for health care students. Resuscitation 1999;41:19-23.

6. Altintas KH et al. The Evaluation of First Aid and Basic Life Support Training for The First Year University Students. Tohoku J Exp Med 2005;205 (2):157-169.
7. Mowbray A, McCullock WJD, Conn AG, Spence AA. Teaching of cardiopulmonary resuscitation by medical students. Med Educ 1987;21:285-7.

8. Stichting Koninklijke Nationale Organisatie voor Reddingwezen en Eerste Hulp bij Ongelukken 'Het Oranje Kruis'. Oranje Kruisboekje 25e druk, Officiële handleiding tot het verlenen van eerste hulp. Utrecht/Zutphen: Thieme/Meulenhoff: 2006. [Foundation Royal National Organisation of Rescue and First Aid Services, 'The Orange Cross'. Orange Cross Booklet, 25th edition, Official first aid instructions. Utrecht/Zutphen: Thieme/Meulenhoff; 2006].

9. Stichting Koninklijke Nationale Organisatie voor Reddingwezen en Eerste Hulp bij Ongelukken 'Het Oranje Kruis: Kernvaardigheden EHBO. Tweede druk Leiden: SMD; 1999. [Royal National Organisation of Rescue and First Aid Services, 'The Orange Cross'. Core first aid skills. 2nd edition. Leiden: SMD; 1999].

10. European Resuscitation Council. European Resuscitation Council guidelines for resuscitation 2005. Resuscitation 2005;67(Suppl 1):S25-37.

11. Van de Velde $\mathrm{S}$ et al. European First Aid Guidelines. Resuscitation 2007 February;72(2):240-251.

12. American College of Surgeons, Committee on Trauma. Trauma Evaluation and Management (TEAM). Program for Medical Students. Chicago: 1999.

13. Stichting Koninklijke Nationale Organisatie voor Reddingwezen en Eerste Hulp bij Ongelukken 'Het Oranje Kruis'. Handleiding voor instructeurs bij de 25e druk van het Oranje Kruis Boekje. Utrecht/Zutphen: ThiemeMeulenhoff; 2006. [[Foundation Royal National Organisation of Rescue and First Aid Services, 'The Orange Cross'. Manual for instructors for 25th edition of Orange Cross booklet. Utrecht/Zutphen: ThiemeMeulenhoff; 2006].

\section{De auteurs:}

P.A. de Ruijter is student geneeskunde en werkzaam bij het Onderwijsinstituut Medische Wetenschappen.*

Drs. S.F.L. van Stigt was als student geneeskunde werkzaam bij het Onderwijsinstituut Medische Wetenschappen UMC St Radboud te Nijmegen, en thans werkzaam als anios bij het ziekenhuis Gelderse Vallei te Ede.

Dr. J. Biert is chirurg-traumatoloog en werkzaam bij de Afdeling Heelkunde - Traumatologie.*

Drs. E.C.T.H. Tan is chirurg-traumatoloog en werkzaam bij de Afdeling Heelkunde - Traumatologie.*

* Allen zijn verbonden aan het Universitair Medisch Centrum St Radboud, Nijmegen. 
Correspondentieadres:

Drs. E.C.T.H. Tan, chirurg-traumatoloog, 690 Afdeling Heelkunde -Traumatologie Universitair Medisch Centrum St Radboud, Nijmegen, postbus 9101, 6500 HB Nijmegen.Tel:024-361387; e-mail:E.Tan@chir.umcn.nl
Belangenconflict: geen gemeld

Financiële ondersteuning: geen gemeld

\section{Summary}

The general public expects health care professionals to be competent to provide first aid including basic life support (BLS). Various studies have shown that junior doctors are deficient in the skills needed to provide first aid and BLS, including cardiopulmonary resuscitation (CPR). The results of these studies have led to the introduction of a compulsory first aid course for all first year medical students of Radboud University Nijmegen Medical Centre. This coincided with the nationwide introduction of the Bachelor-Master (BaMa) structure. The eight 2-hour sessions of the course are taught in the evening and the course includes a theoretical test and a practical exam. In addition to Basic Life Support in accordance with the guidelines of the Dutch Resuscitation Council, various basic life-saving techniques are taught. Second-year medical students attend a mandatory four-hour refresher course including CPR training and additional training in the use of an Automated External Defibrillator (AED). In the third year students attend another 4 hours of refresher training as well as training in paediatric basic life support. The courses are taught by studentinstructors and organised by (2nd to 6th year) medical students, supervised by staff members (two trauma surgeons, a general practitioner and an anaesthesiologist) of Radboud University Nijmegen Medical Centre. The experiences in these courses with the deployment of students as instructors of first aid and BLS training have been favourable. (De Ruijter PA, Stigt SFL van, Biert J, Tan ECTH. Teaching first aid skills to Nijmegen medical students. Dutch Journal of Medical Education 2009;28(2):74-80.) 